\title{
Anne-Babaların Yılmazlık Algılarının Bazı Değişkenler Açısından Incelenmesi
}

\author{
Sema Kaner* \\ Ankara Üniversitesi
}

\author{
Hatice Bayraklı* $^{* *}$ \\ Kemal Yurtbilir İşitme Engelliler \\ Erken Çocukluk Eğitim Merkezi
}

\author{
Cem Oktay Güzeller ${ }^{* * *}$ \\ Akdeniz Üniversitesi
}

Öz

Bu çalışmada, anne-babaların yılmazlık algıları, çocuklarında zihinsel yetersizliğin olup olmamasına, anne ya da baba olmalarına ve yaşlarına göre farklılaşıp farklılaşmadığı incelenmiştir. Araştırma grubu, zihinsel yetersizliği olan çocuğa sahip 105, çocuğu normal gelişim gösteren 419, toplam 524 anne-babadan oluşmaktadır. Araştırmada, Aile Yılmazlık Ölçeği kullanılmıştır. Veriler, MANCOVA ile analiz edilmiştir. Bulgular, Mücadelecilik, Öz-Yetkinlik, Yaşama Bağlllık alt ölçeklerinde ve ölçeğin toplamında normal gelişim gösteren çocuğa sahip anne-babaların kendilerini zihinsel yetersizliği olan çocuklu anne-babalara göre daha yılmaz algıladıklarını; babalara göre annelerin Öz-yetkinlik boyutunda daha yılmaz özelliklere sahip olduklarını; artan yaşla birlikte yılmazlığın öğelerinden olan öz-yetkinlik inançlarının ve yaşama bă̆lılı̆̆ın anne-babalarda azaldığını ortaya koymuştur.

Anahtar Sözcükler: Yılmazlık, anne-baba, zihinsel yetersizliği olan çocuklar, normal gelişim gösteren çocuklar

\begin{abstract}
In this study, parental resilience was investigated in terms of having a child with and without intellectual disability, being mother or father, and parental age. Sample is consisted of 524 parents. 105 parents have children with intellectual disability, and 419 parents have typically developing children. Parental Resiliency Scale is used in this study. Data were analyzed by MANCOVA. Results showed that parents of children without disability perceived themselves more resilient in Challenge, Self-Efficacy, Commitment to Life subscales and also in Total than the other parent group; mothers have more resilient characteristics than fathers in SelfEfficacy subscale; parental resilience decreased by growth in age in Self-Efficacy and Commitment to Life subscales.

\footnotetext{
* Prof. Dr. Ankara Üniversitesi Eğitim Bilimleri Fakültesi Özel Eğitim Bölümü Emekli Öğretim Üyesi, Ankara, E-Posta: semakaner@gmail.com

** Uzm. Kemal Yurtbilir İşitme Engelliler Erken Çocukluk Eğitim Merkezi Anaokulu ve İlköğretim Okulu, Ankara, E-posta: hbayrakli@yahoo.com

*** Yrd. Doç. Dr. Akdeniz Üniversitesi, Eğitim Fakültesi, Eğitim Bilimleri Bölümü, Antalya, E-posta: cguzeller@gmail.com
} 


\section{Key Words: Resilience, parents, children with intellectual disability, typically developing children}

Çocuklar ailelerine hem olumlu yaşantılar sağlar hem de onları zorlayan, baskı altına alan talepleriyle stres yaratırlar. Yetersizliği olan çocuklar ise normal gelişen akranlarına göre pek çok ortamda ailelerinin desteğine ve yardımına daha çok gereksinim duyabilirler. Böyle çocuğu olan aileler hem kendilerinin hem de çocuklarının ilave gereksinimleri nedeniyle diğer ailelere göre aile, iş ve sosyal yaşamlarında daha çok stres yaşayabilirler.

Çocukta yanlış bir şeyler olduğunun öğrenilmesi aileler için çok güç ve şok edici bir durumdur (Heiman, 2002). Bazı aileler bu duruma karşı olumsuz tepki vermeyi sürdürür ve çocuğun durumuna uyum sağlayamazken bazıları da etkili başa çıkma yolları kullanır ve denge durumunu yeniden oluşturup bir önceki iyi olma durumuna dönerek işlevlerini başarıyla yerine getirebilirler (Patterson, 2002). Bir diğer deyişle, yaşadıkları tüm zorluklara rağmen ayakta kalıp yetersizliğin yol açtığı zorlukların üstesinde başarıyla gelebilirler; yılmaz (resilient) olabilirler (Patterson, 2002). Yetersizliği olan çocuğu yetiştirmenin güçlükleri olmasına karşın böyle bir çocuğa anne-babalık etmek anne-babaların kişisel gelişimlerine olumlu katkıda bulunabilmekte, başkalarıyla ilişkilerini geliştirebilmekte, yaşama bakışlarında ve yaşam amaçlarında değişiklikler yaratabilmekte, onların değer sistemlerini etkileyebilmektedir (Pakenham, Sofronoff ve Samios, 2004; Scorgie ve Sobsey, 2000).

Yılmazlık (resilience), bir zorluk durumuyla karşılașıldığında bu durumdan daha güçlü bir șekilde çıkmayı, kriz durumunda gelişim göstermeyi ve dayanıklı olmayı sağlayan aktif bir süreç olarak tanımlanmaktadır (Walsh, 2006). Ailelerin gereksinimlerinin, sahip olunan kaynakları aştığı ve ailedeki dengenin bozulduğu durumlarda yaşanan kriz durumu, ailenin işlevlerini kesintiye uğratabileceği gibi geliştirebilmektedir de. Aile, risk içeren bir durumla karşılaştığında gereksinimleri azaltıp yapabileceklerini arttırmak ve/veya gereksinimlerini karşılayacak araçları ya da yolları değiş̧irerek dengeyi yeniden sağlamak yoluyla yılmaz olabilmektedir (Patterson, 2002). Yetersizliği olan çocuk söz konusu olduğunda, anne-babanın bu duruma uyum yapması ve kaynaklar ile gereksinimler arasındaki dengeyi sağlaması gerekmektedir (Kaner, 2010; Patterson, 2002).

Son yıllarda ailelerin yılmazlı̆̆ına ilgi artmaya başlamış olmasına rağmen, yabancı alanyazında yetersizlĭgi olan çocuklu anne-babalarda yılmazlığı inceleyen sınırlı sayıda çalışma olduğu gözlenmektedir (Bower, Chant ve Chantwin, 1998; Campbell-Sills, Forde ve Stein, 2009; Ha, Hong, Seltzer ve Greenberg, 2008; Li-Tsang, Yau ve Yuen, 2001; Olsson ve Hwang, 2008; Olsson, Larsman ve Hwang, 2008; Plumb, 2011; Svavarsdottir ve Rayens, 2003; Tsibidaki ve Tsamparli, 2009; Van Riper, Ryff ve Priadham, 1992). Türkiye'deki yılmazlık çalışmaları incelendiğinde ise bunların ya gençlerle (örn., Dayığlu, 2008; Eminağaoğlu, 2006; Gizir, 2004; Gürgan, 2006; Kaya, 2007; Özcan, 2005; Sipahioğlu, 2008; Yalım, 2007) ya da farklı özellikleri olan yetişkinlerle (örn., Karaırmak, 2007) yürütüldüğü gözlenmektedir. Türkiye'de özel eğitim alanında ise sadece birkaç çalışma göze çarpmaktadır. Bunlardan biri, yetersizliği olan ve olmayan çocuğa sahip bababalarda yılmazlığın göstergelerinden biri olan psikolojik iyi olmayı incelemiştir (Boyraz ve Sayger, 2011). Doğrudan yılmazlığı ele alan ilk çalışmalar ise Kaner ve Bayraklı tarafından başlatılmıştır (Bayraklı, 2010, Bayraklı ve Kaner 2010; Kaner ve Bayraklı, 2009, 2010a, 2010b, 2011). Bu çalışmalarda Kaner ve Bayraklı, sosyal desteklerin ve başa çıkma yollarının yılmazlık ile ilişkisini yetersizliği olan ve olmayan çocuklu annelerde incelemişlerdir.

Anne-babanın cinsiyetinin (Campbell-Sills ve ark.,2009), yaşının (Ha ve ark., 2008), eğitim durumun (Ha ve ark., 2008) yanı sıra çocuğun özelliklerinin de (Ha ve ark., 2008; Patterson, 2002) ailelerin yılmazlıklarını etkilediği gözlenmektedir. Ancak, yılmazlığı bu değişkenlere göre ele alan araştırmalar yabancı alan yazında da sınırlıdır, Türkiye'de ise hiç yapılmamıştır.

Bu çalışmada, yetersizliği olan çocuğa sahip olmanın, anne ya da baba olmanın, anne-babanın yaşının ve eğitim düzeyinin yılmazlık ile ilişkisi incelenmiştir. Çünkü aile üyelerinden birinin yetersizliğinin olması, ailenin diğer üyelerini ve bir bütün olarak aileyi olumlu ya da olumsuz olarak etkileyebilmektedir. Diğer taraftan, anne ya da baba olmaya ilişkin toplumsal rol beklentileri de onların kendilerine ilişkin değerlendirmelerini etkileyebilmektedir. Farklı yaş dönemlerinde bulunan çocukların ve anne-babaların gereksinimlerinin ve yaşama 
ilişkin beklentilerinin farklılaşması nedeniyle anne-babaların_yaşının yılmazlık üzerindeki etkisinin incelenmesi de önemlidir. Eğitim düzeyi ise yaşamın farklı alanlarında çocuğun ve ailenin gelişimine olan katkıları, ailenin hizmetlere ulaşımını sağlayarak yaşamını kolaylaştırması nedeniyle dikkate alınması gereken bir değişkendir. Her ne kadar eğitim ve gelir düzeyi bazı çalışmalarda yılmazlığı etkileyen bir değişken olarak görülmese de (Olsson ve Hwang, 2008; Plumb, 2011; Ryan ve Caltabiano, 2009) genelde bu iki değişkenin yılmazlığın önemli yordayıcılarından olduğu, gelir ve eğitim düzeyi yükseldikçe yılmazlığın da arttığı bulunmuştur (Bahadır, 2009; Boyraz ve Sayger, 2011; Campbell-Sills ve ark., 2009; Çakır, 2009; Wowra ve McCarter, 1999). Bu nedenle, anne-baların eğitim düzeyleri kontrol altına alınarak sözü edilen değişkenler ile yılmazlığın ilişkisi bu araştırmanın inceleme konusunu oluşturmuştur.

\section{Yöntem}

\section{Araştırma Grubu}

Araştırma grubu, Ankara İli merkez ilçe sınırları içerisinde bulunan özel eğitim okullarında eğitim gören zihinsel yetersizliği olan $(n=105, \% 20.0)$ ve ilköğretim okullarına devam eden normal gelişim gösteren $(n=419$, \%80.0) toplam 524 öğrencinin anne-babalarından oluşmaktadır. Anne-babaların yaş ranjları, ortalamaları ve standart sapmaları sirasiyla $20-63,38.86$ ve $7.45^{\prime}$ dir.

Anne-babaların tanımlayıcı özelliklerrine ilişkin dağılımları Tablo 1'de verilmiştir.

Tablo 1

Anne-Babaların Tanımlayıcı Özellikleri

\begin{tabular}{|c|c|c|c|c|c|c|c|}
\hline \multicolumn{2}{|c|}{ Bağımsız Değişkenler } & \multicolumn{2}{|c|}{$\begin{array}{l}\text { Yetersizliği olan çocuklu anne- } \\
\text { babalar }\end{array}$} & \multicolumn{2}{|c|}{$\begin{array}{c}\text { Yetersizliği olmayan çocuklu } \\
\text { anne-babalar }\end{array}$} & \multicolumn{2}{|c|}{ Toplam } \\
\hline & & $\mathrm{n}$ & $\%$ & $\mathrm{n}$ & $\%$ & $\mathrm{n}$ & $\%$ \\
\hline \multirow[t]{2}{*}{ Cinsiyet } & Kadın & 72 & 22.6 & 246 & 77.4 & 318 & 60.7 \\
\hline & Erkek & 33 & 16.0 & 173 & 84.0 & 206 & 39.3 \\
\hline \multirow[t]{3}{*}{ Yaş } & 35 ve altı & 40 & 22.7 & 136 & 77.3 & 176 & 33.6 \\
\hline & $36-41$ & 40 & 23.1 & 133 & 76.9 & 173 & 33.0 \\
\hline & 42 ve üstü & 25 & 14.3 & 150 & 85.7 & 175 & 33.4 \\
\hline \multirow{3}{*}{$\begin{array}{l}\text { Eğitim } \\
\text { durumu }\end{array}$} & İlköğretim & 60 & 46.1 & 70 & 53.9 & 130 & 24.8 \\
\hline & Lise & 31 & 20.4 & 121 & 79.6 & 152 & 29.0 \\
\hline & $\begin{array}{l}\text { Yüksek okul } \\
\text { ve sonrası }\end{array}$ & 14 & 5.8 & 228 & 94.2 & 242 & 46.2 \\
\hline Toplam & & 105 & 20 & 419 & 80 & 524 & 100 \\
\hline
\end{tabular}

Veri Toplama Araçları

Aile Yılmazlık Ölçeği (AYÖ): Kaner ve Bayraklı (2010b) tarafindan geliştirilen AYÖ, toplam 37 maddeden ve Mücadelecilik, Yaşama Bağlılık, Öz-Yetkinlik ve Kontrol olmak üzere dört alt ölçekten oluşmaktadır. Beşli Likert tipi bir ölçek olan AYÖ’nden yüksek puan almak anne-babalarda yılmazlığın yüksek olduğunu ifade etmektedir (beni çok iyi tanımlıyor-5 puan, beni hiç tanımlamıyor-1 puan).

Ölçek maddelerine uygulanan madde analizi sonucunda elde edilen madde-toplam korelasyonları Mücadelecilik için 0.451-0.689, Öz-Yetkinlik için 0.468-0.697, Yaşama Bağl1lık için 0.387-0.637 ve Kontrol için 0.339-0.408 arasındadır. Bu değerler ölçeğin tümü için 0.378-0.689 arasında değişmektedir. 
AYÖ’nün yapı geçerliği önce Temel Bileşenler Analiziyle incelenmiş, daha sonra ortaya çıkan yapıların doğruluğu Doğrulayıcı Faktor Analiziyle-DFA test edilmiştir. DFA sonucu elde edilen uyum indeks değerleri Kaykare/Sd=1300.96/620=2.1; RMSEA: 0.046; RMR: 0.044; NFI=0.84; NNFI: 0.90; CFI: 0.91; GFI: 0.88; AGFI: $0.87^{\prime}$ dir.

Ölçeğin aynılık geçerliği Anababalık Yetkinliği Ölçeği ( $\mathrm{r}=0.18-0.50, \mathrm{p}<0.01)$ ve Öğrenilmiş Güçlülük Ölçeği $(r=0.45-0.58, p<0.0)$ ile ayrılık geçerliği ise Beck Depresyon Ölçeği $(r=-0.18$ ile $-0.36, p<0.001)$ ile incelenmiştir. AYÖ'nün Cronbach alfa katsayıları 0.54-0.91; test-tekrar test güvenirlik değerleri ise 0.33-0.80 arasında değişmekte olup tümü anlamlıdır.

\section{Verilerin analizi}

Anne-babaların eğitim durumları kontrol altına alınıp, onların yılmazlık algılarının çocuklarının engelli olup olmamasına, anne ya da baba olma durumlarına ve yaşlarına göre farklılaşıp farklılaşmadığı MANCOVA ile incelenmiştir. Anlamlı çıkan farklarının kaynağı Tukey-Kramer testi ile değerlendirilmiştir.

\section{Bulgular}

Anne-babaların AYÖ’den aldıkları puanların ortalamaları ve standart sapmaları Tablo 2'de, anne-babaların eğitim durumları kontrol altına alınıp yılmazlık algılarının çocuklarının zihinsel yetersizliği olup olmamasına, anne ya da baba olmalarına ve yaşlarına göre farklılaşıp farklılaşmadığına ilişkin MANCOVA sonuçları Tablo 3'de verilmiştir.

Tablo 2

Anne-Babaların AYÖ'den Aldıkları Puanların Ortalamaları ve Standart Sapmaları

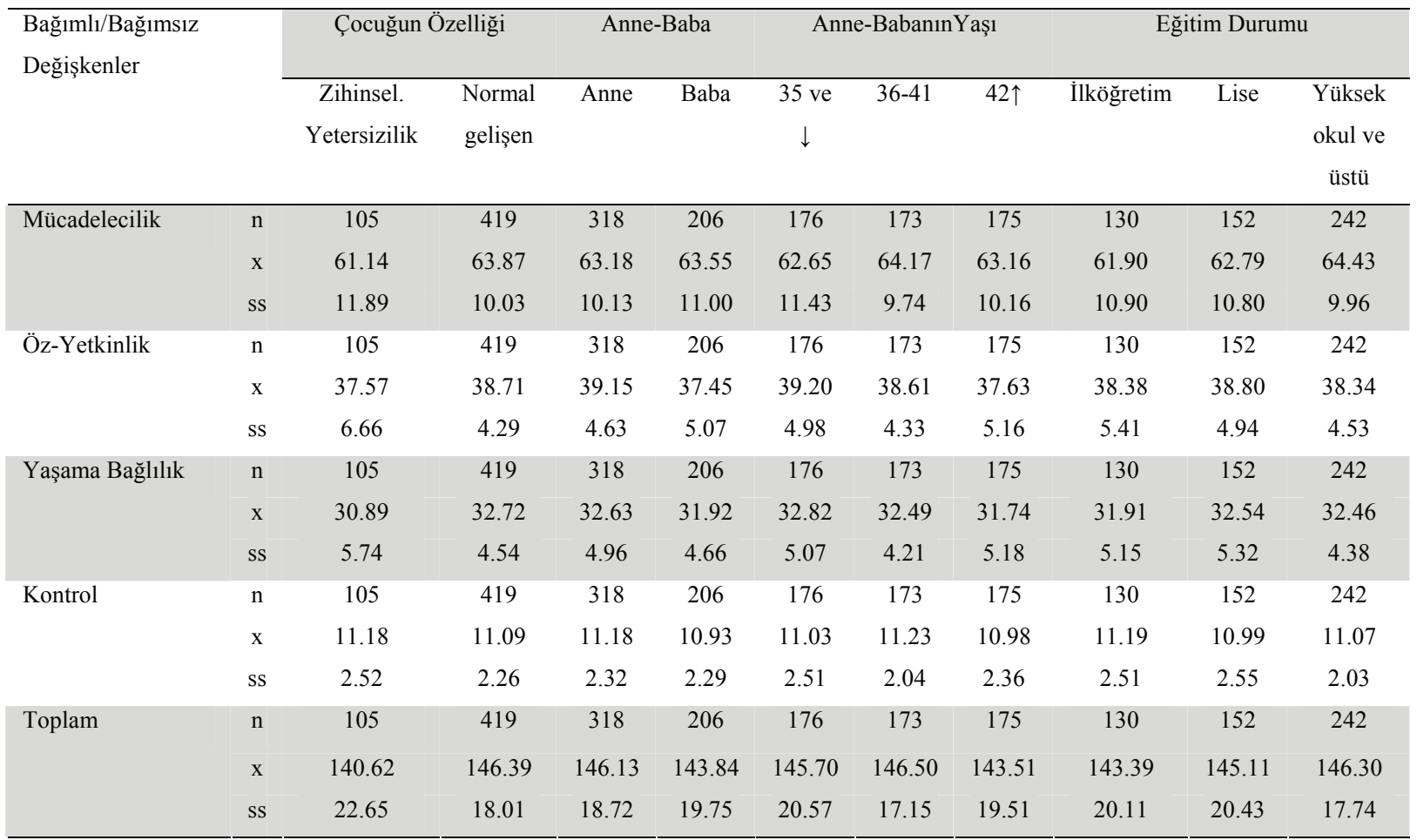


Tablo 3

MANCOVA Sonuçları

\begin{tabular}{|c|c|c|c|c|c|}
\hline \multicolumn{6}{|c|}{ Mücadelecilik } \\
\hline Bağımsız Değ. & KT & $\mathrm{Sd}$ & $\mathrm{KO}$ & $\mathrm{F}$ & $\mathrm{p}$ \\
\hline Çocuğun özelliği(Çö) & 413.850 & 1 & 413.850 & 3.788 & 0.052 \\
\hline Anne-Baba (AB) & 119.654 & 1 & 119.654 & 1.095 & 0.296 \\
\hline Yaş (Y) & 366.149 & 2 & 185.075 & 1.676 & 0.188 \\
\hline Eğitim Düzeyi & 212.190 & 1 & 212.190 & 1.942 & 0.164 \\
\hline ÇÖ X AB & 228.047 & 1 & 228.047 & 2.087 & 0.149 \\
\hline ÇÖ X Y & 130.399 & 2 & 65.200 & 0.597 & 0.551 \\
\hline $\mathrm{AB} X \mathrm{Y}$ & 134.834 & 2 & 67.417 & 0.617 & 0.540 \\
\hline ÇÖ X AB X Y & 183.190 & 2 & 91.595 & 0.838 & 0.433 \\
\hline Hata & 55834.235 & 511 & 109.265 & & \\
\hline Toplam & 2158654.000 & 524 & & & \\
\hline Düzeltilmiş. Toplam & 57422.847 & 523 & & & \\
\hline \multicolumn{6}{|c|}{ Öz-Yetkinlik } \\
\hline Bağımsız Değ. & KT & $\mathrm{Sd}$ & $\mathrm{KO}$ & F & $\mathrm{p}$ \\
\hline Çocuğun özelliği(Çö) & 176.415 & 1 & 176.415 & 7.712 & 0.006 \\
\hline Anne-Baba (AB) & 201.124 & 1 & 201.124 & 8.793 & 0.003 \\
\hline Yaş (Y) & 204.255 & 2 & 102.127 & 4.465 & 0.012 \\
\hline Eğitim Düzeyi & 3.220 & 1 & 3.220 & 0.141 & 0.708 \\
\hline ÇÖ X AB & 5.555 & 1 & 5.555 & 0.243 & 0.622 \\
\hline ÇÖ X Y & 74.508 & 2 & 37.254 & 1.629 & 0.197 \\
\hline $\mathrm{AB} X \mathrm{Y}$ & 1.330 & 2 & 0.665 & 0.029 & 0.971 \\
\hline ÇÖ X AB X Y & 0.633 & 2 & 0.316 & 0.014 & 0.986 \\
\hline Hata & 11688.779 & 511 & 22.874 & & \\
\hline Toplam & 788382.000 & 524 & & & \\
\hline Düzeltilmiş. Toplam & 12452.809 & 523 & & & \\
\hline \multicolumn{6}{|c|}{ Yaşama Bağlılık } \\
\hline Bağımsız Değ. & KT & $\mathrm{Sd}$ & $\mathrm{KO}$ & $\mathrm{F}$ & $\mathrm{p}$ \\
\hline Çocuğun özelliği(Çö) & 191.139 & 1 & 191.139 & 8.344 & 0.004 \\
\hline Anne-Baba (AB) & 0.163 & 1 & 0.163 & 0.007 & 0.933 \\
\hline Yaş (Y) & 168.900 & 2 & 84.450 & 3.687 & 0.026 \\
\hline Eğitim Düzeyi & 0.897 & 1 & 0.897 & 0.039 & 0.843 \\
\hline ÇÖ X AB & 68.078 & 1 & 68.078 & 2.972 & 0.085 \\
\hline ÇÖ X Y & 82.431 & 2 & 41.215 & 1.799 & 0.166 \\
\hline $\mathrm{AB} X \mathrm{Y}$ & 8.236 & 2 & 4.118 & 0.180 & 0.836 \\
\hline ÇÖ X AB X Y & 5.401 & 2 & 2.701 & 0.118 & 0.889 \\
\hline Hata & 11705.262 & 511 & 22.907 & & \\
\hline Toplam & 560689.000 & 524 & & & \\
\hline Düzeltilmiş. Toplam & 12337.090 & 523 & & & \\
\hline
\end{tabular}




\begin{tabular}{|c|c|c|c|c|c|}
\hline \multicolumn{6}{|c|}{ Kontrol } \\
\hline Bağımsız Değ. & KT & $\mathrm{Sd}$ & $\mathrm{KO}$ & $\mathrm{F}$ & $\mathrm{p}$ \\
\hline Çocuğun özelliği(ÇÖ) & 1.518 & 1 & 1.518 & 0.280 & 0.597 \\
\hline Anne-Baba (AB) & 3.921 & 1 & 3.921 & 0.723 & 0.395 \\
\hline Yaş $(\mathrm{Y})$ & 3.604 & 2 & 1.802 & 0.332 & 0.717 \\
\hline Eğitim Düzeyi & 1.189 & 1 & 1.189 & 0.219 & 0.640 \\
\hline ÇÖ X AB & 0.166 & 1 & 0.166 & 0.031 & 0.861 \\
\hline ÇÖ X Y & 1.156 & 2 & 0.578 & 0.107 & 0.899 \\
\hline $\mathrm{AB} X \mathrm{Y}$ & 7.989 & 2 & 3.994 & 0.737 & 0.479 \\
\hline ÇÖ X AB X Y & 0.650 & 2 & 0.325 & 0.060 & 0.942 \\
\hline Hata & 2769.599 & 511 & 5.420 & & \\
\hline Toplam & 67113.000 & 524 & & & \\
\hline Düzeltilmiş. Toplam & 2803.792 & & & & \\
\hline \multicolumn{6}{|c|}{ Toplam } \\
\hline Bağımsız Değ. & KT & $\mathrm{Sd}$ & $\mathrm{KO}$ & F & $\mathrm{p}$ \\
\hline Çocuğun özelliği(Çö) & 2370.030 & 1 & 2370.030 & 6.516 & 0.011 \\
\hline Anne-Baba (AB) & 756.487 & 1 & 756.487 & 2.080 & 0.150 \\
\hline Yaş (Y) & 1779.082 & 2 & 889.541 & 2.446 & 0.880 \\
\hline Eğitim Düzeyi & 159.481 & 1 & 159.481 & 0.438 & 0.508 \\
\hline ÇÖ X AB & 74.440 & 1 & 77.440 & 0.213 & 0.645 \\
\hline ÇÖ X Y & 702.630 & 2 & 351.315 & 0.966 & 0.381 \\
\hline $\mathrm{AB} X \mathrm{Y}$ & 86.035 & 2 & 43.017 & 0.118 & 0.888 \\
\hline ÇÖ X AB X Y & 267.241 & 2 & 133.620 & 0.367 & 0.693 \\
\hline Hata & 185871.731 & 511 & 363.741 & & \\
\hline Toplam & 11244320.000 & 524 & & & \\
\hline Düzeltilmiş. Toplam & 191811.595 & 523 & & & \\
\hline
\end{tabular}

Tablo 2 ve 3'deki sonuçlarda da gözlendiği gibi Mücadelecilik $[\mathrm{F}(1,511)=3.788, \mathrm{p}<0.052]$, Öz-Yetkinlik $[\mathrm{F}(1,511)=7.712, \mathrm{p}<0.006]$, Yaşama Bağlllık $[\mathrm{F}(1,511)=8.344, \mathrm{p}<0.004]$ alt ölçeklerinde ve ölçeğin Toplamında $[\mathrm{F}(1,511)=6.516, \mathrm{p}<0.011]$ normal gelişen çocukların anne-babalarının yılmazlık puan ortalamaları (sırasıyla 63.87, 38.71, 32.72, 146.39), zihinsel yetersizliği olan çocukların anne-babalarının puan ortalamalarından (sırasıyla 61.14, 37.57, 30.89, 140.62) anlamlı olarak daha büyüktür.

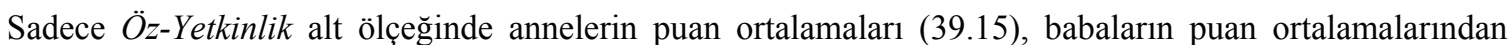
(37.45) anlamlı olarak daha yüksek bulunmuştur $[\mathrm{F}(1,511)=8.793, \mathrm{p}<0.003]$.

Öz-Yetkinlik $[F(2,511)=4.465, p<0.012]$ ve Yaşama Bağll1ık $[F(2,511)=3.687, p<0.026]$ alt ölçeklerinde yaş grupları arasındaki farklar anlamlı bulunmuştur. Bu farklılıkların kaynağı Tukey-Kramer Testi ile incelenmiş ve Öz-Yetkinlik alt ölçeğinde 35 yaş ve altında olan anne-babaların puan ortalamaları (39.20), hem 36-41 yaş grubunun (38.61) hem de 42 yaş ve üzeri olan anne-babaların puan ortalamalarından (37.63) anlamlı olarak daha yüksek hesaplanmıştır. Yaşama Bağlllık alt ölçeğinde de 35 yaş ve altında olan anne-babaların puan ortalamaları (32.82), 42 yaş ve üzeri olan anne-babaların puan ortalamalarından (31.74); 36-41 yaș grubunun puan ortalamaları da (32.49), 42 yaş ve üzeri olan anne-babaların puan ortalamalarından (31.74) anlamlı olarak büyük bulunmuştur. 
Anne-babaların çocuklarının engelli olup olmaması, anne ya da baba olma durumları ve anne-babaların yaşları gibi değişkenlerin hiçbirisinin ortak etkileri anlamlı değildir.

\section{Sonuç ve Tartışma}

Bu çalışmada, anne-babaların çocuklarının yetersizliğinin olup olmaması, anne ya da baba olmaları, yaşları ve eğitim düzeyleri bağımsız değişkenlerine göre katılımcıların yılmazlık algıları MANCOVA ile incelenmiştir.

Araştırmanın ilk bulgusu, Kontrol alt ölçeği dışında tüm alt ölçeklerde ve ölçeğin toplamında normal gelişim gösteren çocuklu anne-babaların kendilerini, yetersizliği olan çocuklu anne-babalara göre daha yılmaz özelliklere sahip bireyler olarak algılamalarıdır. Son yıllarda ailelerin yılmazlığıyla ilgili çalışmalara ilgi artsa da, önceden de belirtildiği gibi yetersizliği olan çocuklu ailelerinin yılmazlığıyla ilgili çalışmalar son derece sinırlıdır (Örn., Bayraklı, 2010; Bower ve ark., 1998; Campbell-Sills ve ark., 2009; Ha ve ark., 2008; Kaner ve Bayrakl1, 2010b, 2011; Li-Tsang ve ark., 2001; Olsson ve Hwang, 2008; Olsson ve ark., 2008; Plumb, 2011; Svavarsdottir ve Rayens, 2003; Tsibidaki ve Tsamparli, 2009; Van Riper ve ark., 1992). Bu da bu çalışmanın bulgularını alanyazın doğrultusunda değerlendirmeyi güçleçtirmektedir.

Çocukların hangi yetersizlik türüne sahip olduklarını dikkate alınmadığında, çalışmaların bazılarında, burada sunulan çalışmanın bulgusuyla aynı yönde sonuca ulaşıldığı bir diğer deyişle, normal gelişim gösteren çocukların anne-babalarının kontrol grubu anne-babalarına göre daha yılmaz özelliklere sahip kişiler olarak değerlendirdikleri gözlenmektedir (Örn., Friborg, Hjemdal, Rosenvinge ve Martinussen, 2003; Ha ve ark., 2008; Kaner ve Bayraklı, 2010a; Olsson ve ark., 2008). Ancak, iki grup anne-baba arasında fark olmadığını gösteren aksi yönde bulgular da elde edilmiştir (Bower ve ark., 1998; Boyraz ve Sayger, 2011; Patterson, 2002; Tsibidaki ve Tsamparli, 2009; Van Riper ve ark., 1992). Hatta, yetersizliği olan çocuklu anne-babalar tarafindan yazılan kitapları inceleyen Mullins (1987), bu anne-babaların çocuklarındaki yetersizlik durumunu kabullendiklerini ve olumlu anlamlar yüklediklerini, aile olarak birbirlerine daha yakın olduklarını, engelin türü ve düzeyi ne olursa olsun yaşamlarının daha da zenginleștiğini ve anlam kazandığını ifade eden yılmaz anne-babalar olduklarını belirtmişler ve yetersiz çocuğu olan ailelerin, kontrol grubu ailelerine göre, günlük yaşamla başa çıkmada güçlük yaşayacakları düşüncesinin artık bir mit olduğu sonucuna ulaşmışlardır. Bir diğer deyişle, yetersizliğe sahip çocuğu olan her aile stres yaşayacak demek değildir. Bazen de, böyle bir çocuğa sahip olmanın aileye olumlu katkıları olmakta, bu çocuklar aile üyelerini birbirlerine daha çok yakınlaştırmakta ve onları ortak bir hedef etrafinda toplamaktadır (Bailey, 1988; Gallagher, Beckman ve Cross, 1983).

Farklı özellikleri olan çocuklara sahip anne-babaların bulgularını doğrudan alt ölçekler açısından ayrı ayrı değerlendirmek istersek, bu bulgularımızı kıyaslayabileceğimiz çok az çalışma olduğunu söyleyebiliriz. Yetersizliği olan çocuklu anne-babaların anababalık yetkinliğiyle ilgili çalışmalar son derece sınırlıdır ve daha çok da anneler ile yürütülmüştür. Ulaşılan çalışmalarda, davranış bozukluğu (Sanders ve Woolley, 2004), gelişim geriliği (Olsson ve Hwang, 2002) olan çocukların annelerinin, zihinsel, işitsel, bedensel gibi farklı yetersizlik türlerine sahip (Kaner, Şekercioğlu ve Yellice-Yüksel 2007) ve dikkat eksikliği-hiperaktivite bozukluğu olan (Rogers, Wiener, Marton ve Tannock, 2009) çocukların anne-babalarının anababalık yetkinliği inançlarının tıpkı bu çalışmada olduğu gibi normal gelişen çocukların anne-babalarından daha düşük olduğu bulunmuştur.

Mücadelecilik ve yaşama bağlılık, yılmazlı̆̆ın vazgeçilmez ögelerindendir. Bu çalışmada, çocukları normal gelişim gösteren anne-babalara göre kronik sorunu olan çocukların anne-babalarının kendilerini daha az mücadeleci ve daha az iyimser algıladıkları bulunmuştur. Yetersizliği olan ve olmayan çocuklara sahip annebabaları benzer alt ölçekler açısından inceleyen çalışmalara rastlanmadığı için bu bulgu alanyazın ile kıyaslanamamıştır. Ancak, bu araştırmanın bulgusuna dayanarak çocuğun kronik bir sorununun olmasının annebabaların yetkinlik algılarını olumsuz etkilediği söylenebilir. Yılmazlık, çocuğun sorunlarıyla etkili başa çıkmayı ve etkili problem çözme becerilerini gerektirir. Kronik sorunu olan çocuklarını büyütürken anne-babaların 
gerekli donanımları yoksa kendilerini yetkin, iyimser, mücadeleci ve dayanıklı kısaca yılmaz algılamaları güç görünmektedir.

Lazarus ve Folkman'ın (1984) Uyum Modeline (Adaptation Model) göre stres kaynağıyla (yetersizliği olan çocuk) uzun süreli yaşantısı olan bireyler bu zorluklara daha çok uyum sağlarlar. Zamanla anne-babalar, bu aile koşuluna daha iyi tepkide bulunma becerilerini geliştirerek çocuğun yetersizliğinin yarattı̆̆ strese uyum gösterirler. Birikimli Stres Modeline (Cumulative Stress Model) göre ise uzun süreli strese maruz kalan bireylerde stres birikimli etki yapar ve bu kişiler daha kısa süreli strese maruz kalanlara kıyasla daha kırılgan olurlar (Hoyert ve Seltzer, 1992; Towsend, Noelker, Deimling ve Bass, 1989). Bu nedenle, yetersizliği olan çocuğa anne-babalık etmenin stresi birikimli olarak artar. Bu araştırmanın bulgusu, daha çok Birikimli Stress Modelinin görüşlerini doğrular nitelikte görünmektedir.

Yukarıda sözü edilen bulguyu özel eğitim alanında Türkiye'de verilen hizmetler açısından da değerlendirebiliriz. Türkiye'de yetersizliği olan çocuklara ve ailelere yönelik hizmetlerin henüz onların gereksinimlerini uygun şekilde sistemli olarak karşılayacak düzeyde olmaması onların uyumunu zorlaştırıyor olabilir. Yasalar ve yönetmelikler yetersizliği olan çocuklara ve ailelere yönelik götürülmesi gereken hizmetleri açıkça ifade etmiş olmasına karşın, yeterli eğitsel, profesyonel, sosyal destek hizmetlerinin sağlandığını söyleyemeyiz. Ayrıca, pek çok kültürde bu ailelerin pek çoğunun eğitim ve gelir düzeylerinin de düşük olduğu, daha kalabalık ailelerden geldikleri ve sosyal katılımlarının daha az olduğu yönünde bulgular da vardır (Black ve Ford-Gilboe, 2004; Boyraz ve Sayger, 2011; Campbell-Sills ve ark., 2009; Hatton ve Emerson, 2009; Knestrict ve Kuchey, 2009; Seltzer, Greenberg, Floyd, Pettee ve Hong, 2001). Bu araştırmanın anne-babalarının yaklaşık yarısının (\%46.1) ilköğretim düzeyinde eğitim almış olduklarını hatırlamakta yarar vardır.

Buna karşın, zihinsel engelli olmalarına, öğrenme güçlüğü yaşamalarına hatta düşük gelir, düşük eğitim düzeyi ve yoksulluk gibi olumsuz koşullara rağmen, olumlu destekleyici aile, sosyal ve profesyonel destek çevresine sahip olmanın bu çocukların gelişimine katkıda bulunduğunu ve aileleri güçlendirdiğini, yılmaz kıldığını gösteren bulgular da az değildir (Mullins, 1987; Muir, Tudball ve Robinson, 2008; Raskind, Goldberg, Higgins ve Herman, 1999; Richardson ve Koller, 1992; Werner, 1993). Kısaca, yılmazlık, koruyucu faktörlerle beslenir, risk faktörleriyle engellenir (Benzies ve Mychasiuk, 2009). Bu durumda, yetersizliği olan çocuklar ve aileleri için koruyucu ve destekleyici hizmetleri sağladığımızda ve aileleri güçlendirdiğimizde onların yılmazlıklarını da arttırabiliriz. Ayrıca, her ailenin zaman zaman sorunlar yaşadığını, sorunsuz aile olmadığını ancak sorunlar karşışında kullanılan başa çıkma yollarının ve problem çözme becerilerinin önemli olduğu söylenebilir (Bayraklı, 2010; Bayraklı ve Kaner, 2012; Kaner ve Bayraklı, 2010a; Walsh, 2006). Bu nedenle, farklı özelliklere sahip grupların yılmazlıkların, sahip oldukları sosyal destek sistemlerinin yanı sıra problem çözme ve başa çıkma teknikleriyle birlikte incelemekte yarar vardır.

Araştırmanın ikinci bulgusuna göre anne ya da baba olmak sadece Öz-Yetkinlik alt ölçeğinde fark yaratmıştır. Bu bulguya dayanarak, anne ve ababaların yılmazlık algılarının yılmazlığı oluşturan özelliklerine göre farklılaşabildiğini ve bu ailelerin farklılıklardan çok benzerlikleri olduğunu söyleyebiliriz. Yılmazlığa ilişkin cinsiyet farklılığını inceleyen araştırmalar oldukça sınırlıdır ve çelişkili bulgular vermektedir. Kimileri babaların ve/veya yetişkin erkeklerin annelere ve/veya yetişkin kadınlara göre daha yılmaz olduklarını bildirirken (Bahadır, 2009; Boyraz ve Sayger, 2011; Campbel-Sills ve ark., 2009; Lee, Chen ve Tran, 2008; Olsson ve ark., 2008; Svavarsdottir ve Rayens, 2003), kimileri kadınların lehine olmak üzere aksi yönde sonuçlara ulaşmışlar (Friborg ve ark., 2003), kimileri cinsiyete ilişkin farklılıklar bulamamışlar (Olsson ve Hwang, 2008; Plumb, 2011; Sezgin, 2009; Skehill, 2001; Sojo ve Guarino, 2011; Svavarsdottir ve Rayens, 2003), kimileri de bu çalışmada olduğu gibi yılmazlığın sadece bazı boyutlarında (Ha ve ark., 2008; Hjemdal, Friborg, Stiles, Martinussen ve Rosenvinge, 2006; Markstrom, Marshall ve Tryon, 2000) ya da yaşa bağlı olarak (Lundman, Strandberg, Eisemann, Gustafson ve Brulin, 2007) cinsiyet farkı olduğunu bildirmişlerdir. Yukarıda verilen çalışmalardan sadece dördü anne ve babaların (Boyraz ve Sayger, 2011; Olsson ve ark., 2008; Plumb, 2011; Svavarsdottir ve Rayens, 2005), diğerleri ise farklı gruplarda kadın ve erkeklerin yılmazlık algılarını kıyaslamışır. 
Cinsiyete ilişkin bulgulardaki tutarsızlı̆̆ı, araştırılan grupların farklı özelliklere sahip olmaları (örn., çocuklarının farklı yetersizliğe sahip olmaları; soykırıma maruz kalmaları, bir afetin kurbanları olmaları, yoksul olmaları, belirli bir meslekten olmaları, işsiz olmaları, kurum bakımında büyümüş olmaları gibi), farklı yaş gruplarından gelmeleri ve kullanılan ölçme araçlarındaki farklılıklar olması gibi faktörlere bağlayabiliriz. Bulgulardaki bu çeşitlilik, cinsiyet-yılmazlık ilişkisinin farklı özelliklere sahip yetişkinlerde daha çok çalışılması gerektiğini göstermektedir.

Bu çalışmada, yılmazlığın sadece Öz-Yetkinlik alt boyutunda iki grup arasında annelerin lehine fark bulunmuştur. Anababalık yetkinliğiyle ilgili çok fazla araştırma olmaması, varolan araştırmaların da daha çok anneler ile yapılmış olması (Örn., Chen, Chang, He ve Liu; 2005; Diken, 2009; Gondoli ve Silverberg, 1997; Kendall ve Bloomfield, 2005; Kwok ve Wong, 2000; Montigny ve Lacharite, 2005; Oyserman, Bybee, Mowbray ve Kahng, 2004; Sanders ve Woolley, 2004) bu araştırmanın bulgularının değerlendirilmesini zorlaştırmaktadır. Sınırlı alanyazın içerisinde bu çalışmanın bulgusunu destekleyen üç çalışmaya ulaşılmıştır. Bunlardan ilki, beş aylık bebeklerin (Boivin ve ark., 2005); ikincisi, 8-9 yaşlarındaki çocukların (Lynch, 2002), üçüncüsü ise genç yetişkin çocukların (Riggio ve Desrochers, 2006) anne ve babalarıla yürütülmüştür. Anne ve babaların yetkinlik inançları arasında fark olmadı̆̆ını (Johnston ve Mash, 1989; Rogers ve ark., 2009; Sofronoff ve Farbotko, 2002) ve babaların daha yüksek yetkinlik inancına sahip olduğunu gösteren araştırmalarda da (Elek, Hudson ve Bouffard, 2003; Goodwin, Ostrom ve Scott, 2009; Rothaupt ve Young, 2007) farklı özelliklere sahip çocukları olan anne ve babalar araştırma gruplarını oluşturmuştur.

$\mathrm{Bu}$ araştırmada anne ve babaların yılmazlık algılarının farklı olmaktan çok benzer olmasının nedeni, annelerin ve babaların yılmazlığın farklı ögelerine daha çok sahip olmalarıyla ilgili olabilir. Örneğin, yaşlarını dikkate almadan kızların/kadınların yılmazlığın temel özelliklerinden olan empati, duyarlık, iletişim, yardım arama, sosyal desteklere ulaşma, eğitsel beklentilere sahip olma gibi özelliklere, erkeklerin ise kişisel yeterlik, psikolojik iyilik hali gibi özelliklere daha çok sahip oldukları gözlenmektedir (Friborg ve ark., 2003; Önder ve Gülay, 2008; Sun ve Stewart, 2007; Svavarsdottir ve Rayens, 2005). Ayrıca, kadınların geleneksel rolleri nedeniyle çocuklarının bakımından ve eğitiminden daha çok sorumlu olmaları, sosyal destekleri daha çok arayıp onlara ulaşmaları, bunların yanı sıra çalışma yaşamına da aktif olarak katılmaya başlamış olmaları nedeniyle; erkeklerin ise zayıflıklarını göstermeme, güçlü olma yönünde toplumsallaştırılmaları, ev dışında evin geçimini sağlamaktan sorumlu olmaları ancak çocuklara bakım verme işine de giderek daha çok katılıyor olmaları her iki cinsiyeti de farklı yönlerden yılmaz kılıyor olabilir.

Öz-Yetkinlik alt ölçeği dışında anne ve babaların yılmazlık algıları arasında fark bulunmamasının yanı sıra yetersizliği olan ve olmayan çocuğa sahip olmak ve anne baba olmak değişkenlerinin etkileşim etkisi de anlamlı çıkmamıştır. Yani çocukları normal gelişsin ya da gelişmesin anne ve babalar yılmazlık açısından kendilerini benzer şekilde algılamaktadırlar. Bu bulgu ise anne ve babaların yılmazlık algılarının farklılaşmadığını ortaya koyan araştırmaların bulgularını desteklemektedir (Olsson ve Hwang, 2008; Plumb, 2011; Sezgin, 2009; Skehill, 2001; Sojo ve Guarino, 2011; Svavarsdottir ve Rayens, 2003). Yine de farklı yetersizliği olan ve olmayan çocukların anne ve babalarının sosyal kimliklerinin yılmazlık ile ilişkisinin pek çok araştırmada incelenmesine gereksinim vardir.

Yılmazlık-yaş ilişkisiyle ilgili alanyazın incelendiğinde karşımıza yine çelişkili bulgular çıkmaktadır. Araştırmalar genel olarak artan yaşla birlikte yılmazlığın da arttığını göstermektedir (Campbell-Sills ve ark., 2009; Friborg ve ark., 2003; Ha ve ark., 2008; Lloyd ve Hastings, 2009; Lee ve ark., 2008; Lundman ve ark., 2007; Onat, 2010). Bunun yanında, bu çalışmada olduğu gibi bazı yılmazlık özellikleri açısından genç yaştaki yetişkinlerin kendilerini daha yılmaz özelliklere sahip olarak algıladıkları da bildirilmektedir (Lee, Chen ve Tran, 2008). Yılmazlığın yaşa bağlı olarak değişmediğine işaret eden çalışmalar da azımsanmayacak ölçüdedir (Boyraz ve Sayger, 2011; Hystad, Eid, Johnsen, Laberg ve Bartone, 2010; Kaner ve Bayrakl1, 2010a; Sojo ve Guarino, 2011; Trute, 1990). 
Bu çalışmada, ilerleyen yaşla birlikte yılmazlığın önemli iki ögesi olan öz-yetkinliğin ve yaşama bağlılığın giderek azaldığı bulunmuş, diğer alt ölçeklerde ve toplam yılmazlık puanında yaşa ilişkin farklılık belirlenmemiştir. $\mathrm{Bu}$ bulgu, yine yılmazlığın farklı özelliklerinin yaşa bağlı olarak değiştiği görüşünü desteklemektedir. Alan yazında yılmazlığın önemli elemanı olan mücadelecilik ile yaş ilişkisini anne ve babalarda irdeleyen bulguya rastlanmamıştır. Öz-yetkinlik ile yaş ilişkisin anne-babalar açısından ele alan birkaç çalışma vardır. Bunlardan sadece biri (Kaner, 2007), bu çalışmada olduğu gibi farklı türde yetersizliği olan ve normal gelişen anne-babaların yetkinlik inançlarının artan yaşla birlikte azaldığı sonucuna ulaşmıştır (Kaner, 2007). Diğer çalışmalar normal gelişim gösteren anne-babalar ile yapılmış ve anne-babanın yaşının onların yetkinlik inancını yordamadığı bildirilmiştir (Coleman ve Karraker, 2000; Kendall ve Bloomfield, 2005). Bu sonucu, artan yaşla birlikte işlevlerdeki değişmelerle açıklayabiliriz. Her ne kadar 60'lı yaşlardan sonra hala pek çok insan sağlıklı bir yaşama sahip olsa da (Walsh, 2006) insanlar yaşlandıkça yaşlılıkla ilgili sorunları yaşamaya başlarlar, işlevlerini giderek kaybederler ve bakım geresinimlerini daha az karşılar duruma gelirler. Artan yaşla birlikte deneyim ve başa çıkma becerileri gelişmiş olsa bile işlevlerdeki gerileme onların yetkinliklerini, dayanıklılıklarını, yılmazlıklarını yaşama olan bağlılıklarını olumsuz olarak etkiliyor olabilir. Bunun yanı sıra yine Birikimli Stress Modelinin görüşlerine dayanarak uzun süreli yetersizliği olan bir çocukla yaşamanın sonucunda bu ailelerin daha kırılgan, daha kolay incinebilir oldukları söylenebilir.

Diğer taraftan, yetersizliği olmayan çocuklar meslek-iş sahibi olup evden ayrılmalarıyla birlikte ailelerinin bakım sorumluluğu ortadan kalkmaktadır. Ancak, zihinsel yetersizlik ortadan kaldırılabilecek bir durum değildir, süreklidir ve yaşam boyu sürer. Yaş ilerledikçe anne-babalar yetersizliği olan çocuklarına bakım geresinimlerini daha az karşılar duruma gelirler. Buna bağlı olarak, iki gruptaki anne-babaların yılmazlık algılarının farklılaşması beklenebilir. Ancak, bu çalışmanın diğer bulguları durumun böyle olmadığını göstermektedir. Bu çalışmada, yaşın yılmazlık üzerindeki temel etkisinin anlamlı bulunmamasının yanı sıra, yaşın diğer değişkenler ile etkileşimi de (anne-baba olmak, yetersizliği olan ya da olmayan çocuğa sahip olmak) anlamlı bulunmamıştır. Bir diğer deyişle, çocuğun normal gelişip gelişmemesi, anne ya da baba olmak ve farklı yaş dönemlerinde olmak katılımcıların yılmazlıklarını etkilememektedir.

$\mathrm{Bu}$ çalışmada, çocukların yaşlarıyla ilgili bilgi bulunmamaktadır. Ancak, normal gelişen çocukların ilköğretim okullarında, zihin engelli çocuklarında özel eğitim okullarında eğitim aldıklarını düşünürsek, her iki gruptaki anne-babaların çocuklarının yaşlarının ergenlik öncesiyle sınırlı olduğu söylenebilir. Bu durumda, yetersizliği olan ve olmayan çocukların ailelerini ileri yaşlarda da yılmaz kılan özelliklerin sorgulanması, ailelerin sahip oldukları destek sistemlerinin incelenmesi gerekebilir. Ayrıca, yaş-yılmazlık ilişkisinin farklı türde ve yaşta yetersizliği olan ve normal gelişen çocuklu anne-babalarda ayrı ayrı ve boylamsal olarak incelenmesi yılmazlığın dinamiklerini anlamamıza katkıda bulunacaktır.

Her çalışmada olduğu gibi bu çalışmanın da bazı sınırlılıkları vardır. Bunlardan ilki, yetersizliğin sadece zihinsel engel ile sınırlandırılmış olmasıdır. Çocuğun yaşı, cinsiyeti, yetersizliği olan çocuğa tanı koyulduğu zaman anne-babanın ve çocuğun kaç yaşında olduğu, farklı yetersizlik türleri, ailenin gelir düzeyi, anne-babanın sağlık durumu, ailede yetersizliği olan başka birey olup olmadığı gibi ailenin diğer yapısal özelliklerinin de analiz edilmesi yılmazlık hakkındaki bilgilerimizi zenginleştirecektir. Diğer sinırlılık ise normal gelişen çocuğu olan anne-babaların sayılarının, yetersizliği olan çocuklu anne-babaların sayısının dört katı olmasıdır.

Anne-babaların yılmazlığıyla ilgili çalışmalar sınırlı olduğundan ve anne-babaların ve çocukların özelliklerinin yılmazlıkla olan ilişkisinin çok az incelendiğinden söz etmiştik. İleri çalışmalarda, hem annebabalara hem de çocuklarına ilişkin farklı değişkenlerin birlikte yılmazlığa katkılarını inceleyen araştırmaların anne-babaların yılmazlık algılarına ilişkin sorulara açıklık getireceği beklenebilir. 


\section{KAYNAKLAR}

Bahadır, E. (2009). Sağlıkla ilgili fakültelerde eğitime başlayan öğrencilerin psikolojik sağlamlık düzeyleri. Yayınlanmamış yüksek lisans tezi, Hacettepe Üniversitesi, Ankara.

Bailey, D. B. (1988). Assessing family stress and needs. In D. B. Bailey, R. N. Simeonsson (Eds.). Family assessment in early intervention (pp. 95-118). Columbus: Merrill Publishing Company.

Bayraklı, H. (2010). Zihinsel engelli ve engelli olmayan çocuğa sahip annelerde yllmazliğa etki eden değiş̧kenlerin incelenmesi. Yayınlanmamış yüksek lisans tezi, Ankara Üniversitesi Ankara.

Bayrakl1, H. ve Kaner, S. (2010). Zihinsel engelli ve engelli olmayan çocuğa sahip annelerde yılmazlığa etki eden değişkenlerin incelenmesi. 20. Ulusal Özel Eğitim Kongresi. Öğretmen Yetiştirme: Bildiri Özetleri, Ankara: Kök Yayıncılık, 70-71.

Bayraklı, H. ve Kaner, S. (2012). Zihin engelli ve engelli olmayan çocuğa sahip annelerde yllmazlığa etki eden değişkenlerin incelenmesi. Kuram ve Uygulamada Eğitim Bilimleri, 12 (2), 1-18.

Benzies, K., \& Mychasiuk, R. (2009). Fostering family resiliency: A review of the key protective factors. Child and Family Social Work, 14, 103-114.

Black, C., \& Ford-Gilboe, M. (2004). Adolescent mothers: Resilience, family health work and health-promoting practices. Journal of Advanced Nursing, 48(4), 351-360.

Boivin, M., Perusse, D., Dionne, G., Saysset, V., Zoccolillo, M., Tarabulsy, G.M., Tremblay, N., \& Tremblay, R.E. (2005). The genetic-environmental etiology of parents' perceptions and self-assessed behaviors toward their 5-month-old infants in a large twin and singleton sample. Journal of Child Psychology and Psychiatry, 46(6), 612-630.

Bower, A., Chant, D., \& Chantwin, S. (1998). Hardiness in families with and without a child with Down Syndrome. Down Syndrome Research and Practice. 5(2), 71-77.

Boyraz, G., \& Sayger, T.V. (2011). Psychological well-being among fathers of children with and without disabilities: The role of family cohesion, adaptability, and paternal self-Efficacy. American Journal of Men's Health, 5(4), 286-296.

Campbell-Sills, L., Forde, D.R., \& Stein, M.B. (2009). Demographic and childhood environmental predictors of resilience in a community sample. Journal of Psychiatric Research, 43, 1007-1012.

Chen, X., Chang, L., He, Y., \& Liu, H. (2005). Peer group as a context: Moderating effects on relations between maternal parenting and social and school adjustment in Chinese children. Child Development, 76(2), 417434.

Coleman, P.K., \& Karraker, K. H. (2000). Parenting self-efficacy among mothers of school-age children: Conceptualization, measurement, and correlates. Family Relations, 49, 13-24.

Çakır, S. G. (2009). Factors and mechanisms of resilience among Turkish migrant women in the UK. Yayınlanmamış doktora tezi, Ortadoğu Teknik Üniversitesi, Ankara.

Dayığlu, B. (2008). Resilience in university entrance examination applicants: The role of learned resourcefulness, perceived social support and gender. Yayınlanmamış yüksek lisans tezi, Orta Doğu Teknik Üniversitesi, Ankara.

Diken, İ. H. (2009). Turkish mothers' self-efficacy beliefs and styles of interactions with their children with language delays. Early Child Development and Care, 179(4), 425-436. 
Eminağaoğlu, N. (2006). Güç koşullarda yaşayan sokak çocuklarında dayanıklılık (sağlamlık). Yayınlanmamış doktora tezi, Ege Üniversitesi, İzmir.

Elek, S. M., Hudson, D. B., \& Bouffard, C. (2003). Marital and parenting satisfaction and infant care selfefficacy during the transition to parenthood: The effects of infant sex. Issues In Comprehensive Pediatric Nursing, 26, 45-57.

Friborg, O., Hjemdal, O., Rosenvinge, J. H., \& Martinussen, M. (2003). A new rating scale for adult resilience: What are the central protective resources behind health adjustment? International Journal of Methods in Psychiatric Research, 12(2), 65-76.

Gallagher, J. J., Beckman, P., \& Cross, A. H. (1983). Families of handicapped children: Sources of stress and its amelioration. Exceptional Children, 50(1), 10-19.

Gizir, C. (2004). Academic resilience: An investigation of protective factors contributing to the academic achievement of eighth grade students in poverty. Yayınlanmamış doktora tezi, Orta Doğu Teknik Üniversitesi, Ankara.

Gondoli, D. M., \& Silverberg, S. B. (1997). Maternal emotional distress and diminished responsiveness: The mediating role of parenting efficacy and parental perspective taking. Developmental Psychology. 33(5), 861-868.

Goodwin, K. S., Ostrom, L., \& Scott, K. W. (2009). Gender differences in mathematics self-efficacy and back substitution in multiple choice assessment. Journal of Adult Education, 38(1), 22-42.

Gürgan, U. (2006). Grupla psikolojik danışmanın üniversite ögrencilerinin yllmazlık düzeylerine etkisi. Yayınlanmamıs doktora tezi, Ankara Üniversitesi, Ankara.

Ha, J-H., Hong, J., Seltzer, M. M., \& Greenberg, J. S. (2008). Age and gender differences in the well-being of midlife and aging parents with children with mental health or developmental problems: Report of a national study. Journal of Health and Social Behaviors, 49, 301-316.

Heiman, T. (2002). Parents of children with disabilities: Resilience, coping, and future expectattions. Journal of Developmental and Physical Disabilities, 14(2), 159-171.

Hatton, C., \& Emerson, E. (2009). Poverty and the mental health of families with a child with intellectual disabilities. Psychiatry, 8(11), 433-437.

Hjemdal, O., Friborg, O., Stiles, T.C., Martinussen, M., \& Rosenvinge, J.H. (2006). A new scale for adolescent resilience: Grasping the central protective resources behind healthy development. Measrument and Evaluation in Counseling and Development, 39, 84-96.

Hjemdal, O., Friborg, O., Stiles, T.C., Martinussen, M., \& Rosenvinge, J.H. (2006). Resilience predicting psychiatric symptoms: A perspective study of protective study of protective factors and their role in adjustment to stressful life events. Clinical Psychology and Psychotherapy, 13, 194-201.

Hoyert, D. L., \& Seltzer, M. M. (1992). Factors related to the well-being and life activities of family caregivers. Family relations, 41, 74-81.

Hystad, S.W., Eid, J., Johnsen, B.H., Laberg, J.C., \& Bartone, P.T. (2010). Psychometric properties of the revised Norwegian dispositional resilience (hardiness) scale. Scandinavian Journal of Psychology, 51(3), $237-245$.

Johnston, C., \& Mash, E.J. (1989). A measure of parenting satisfaction and efficacy. Journal of Clinical Child Psychology, 18(2), 167-175. 
Kaner, S. (2007). Öğretmenlerin ve anne-babaların öz-yetkinlik inançları, tükenmişlik algıları ve çocukların problem davranışları. Yayınlanmamış Proje Raporu, Proje No: 20060904009

Kaner, S. (Proje Başkanı), Şekercioğlu, G. \& Yellice-Yüksel, B. (2007). Öğretmenlerin ve ana-babaların özyetkinlik inançları, tükenmişlik algıları ve çocukların problem davranışları. Yayınlanmamış Araştırma Projesi. Proje Numarası: 20060904009.

Kaner, S. (2010).Yenilenmiş Ana-Baba Sosyal Destek Ölçeği’nin psikometrik özellikleri. Eğitim ve Bilim, 157 (36), 15-29.

Kaner, S. ve Bayraklı, H. (2009). Engelli ve engelli olmayan çocuklu annelerde yılmazlık, sosyal destek ve stresle başa çıkma becerileri. Eğitim Bilimleri ve Uygulama Dergisi, 8(15), 115-133.

Kaner, S. ve Bayraklı, H. (2010a). Annelerde yılmazlık algısının bazı değişkenlere göre incelenmesi. Yayınlanmamış araştırma raporu.

Kaner, S. ve Bayraklı, H. (2010b). Aile Yılmazlık Ölçeği: Geliştirilmesi, geçerlik ve güvenirliği. Ankara Üniversitesi Ĕ̆itim Bilimleri Fakültesi Özel Eğitim Dergisi, 11 (2), 47-62.

Kaner, S. ve Bayraklı, H. (2011). Anne Yılmazlık Ölçeği’nin psikometrik özellikleri. Eğitim Bilimleri ve Uygulama Dergisi, 9(17), 77-94.

Karairmak, Ö. (2007). Investigation of personal qualities contributing to psychological resilience among earthquake survivors: A model testing study. Yayınlanmamış doktora tezi, Ortadoğu Teknik Üniversitesi, Ankara.

Kaya, N. D. (2007). The role of self-esteem, hope and external factors in predicting resilience among regional boarding elementary school students. Yayınlanmamış yüksek lisans tezi, Ortadoğu Teknik Üniversitesi, Ankara.

Kendall, S., \& Bloomfield L. (2005). Developing and validating a tool to measure parenting self-efficacy. Journal of Advanced Nursing, 51(2), 74-181.

Knestrict, T., \& Kuchey, D. (2009). Welcome to Holland: Characteristics of resilient families raising children with severe disabilities. Journal of Family Studies, 15, 227-244.

Kwok, S., \& Wong, D. (2000). Mental health of parents with young children in Hong Kong: The roles of parenting stress and parenting self-efficacy. Child and Family Social Work, 5, 57-65.

Lazarus, R., \& Folkman, S. (1984). Stress, appraisal, and coping. New York: Free Press.

Lee, E. O., Chen, C., \& Tran, T. V. (2008). Coping with hurricane Katrina: Pysychological distress and resilience among African American evacuees. Journal of Black Psychology, 20(5), 1-19.

Li-Tsang, W. P. C., Yau, M. K. S., \& Yuen, H. K. (2001). Success in parenting children with developmental disabilities: some characteristics, attitudes and adaptive coping skills. The British Journal of Developmental Disabilities, 47(93), 61-71.

Lloyd, T. J., \& Hastings, R. (2009). Hope as a psychological resilience factor in mothers and fathers of children with intellectual disabilities. Journal of Intellectual Disability Research, 53(12), 957-968.

Lundman, B., Strandberg, G., Eisemann, M., Gustafson, Y., \& Brulin, C. (2007). Psychometric properties of the Swedish version of the Resilience Scale. Scand J Caring Sci., 21(2), 229-37.

Lynch, J. (2002). Parents' self-efficacy beliefs, parents' gender, children's reader self-perceptions, reading achievement and gender. Journal of Research in Reading, 25(1), 54-67. 
Markstrom, C.A., Marshall, S.K., \& Tryon, R.J. (2000). Resiliency, social support, and coping in rural lowincome Appalachian adolescents from two racial groups. Journal of Adolescence, 23, 693-703.

Montigny, F., \& Lacharite, C. (2005). Perceived parental efficacy: Concept analysis. Journal of Advanced Nursing, 49(4), 387-396.

Muir, K., Tudball, J., \& Robinson, S. (2008). Family resilience where families have a child (0-8 years) with disability. Report prepared for the Disability Policy and Research Working Group. University of New South Wales, Sydney.

Mullins, J. B. (1987). Authentic Voices From Parents of Exceptional Children. Family Relations, 36, 30-33.

Olsson, M.B., \& Hwang, C.P. (2002). Sense of coherence in parents of children with different developmental disabilities. Journal of Intellectual Disability Research, 46(7), 548-559.

Olsson, M.B., \& Hwang, C.P. (2008). Socioeconomic and psychological variables as risk and protective factors for parental well-being in families of children with intellectual disabilities. Journal of Intellectual Disability Research, 52(12), 1102-1113.

Olsson, M.B., Larsman, P., \& Hwang, P.C. (2008). Relationships among risk, sense of coherence, and wellbeing in parents of children with and without intellectual disabilities. Journal of Policy and Practice in Intellectual Disabilities, 5(4), 227-236.

Onat, G. (2010). Demokratik ve otoriter olarak algılanan ana-baba tutumlarının lise birinci sını öğrencilerinin yılmazlık düzeyine etkilerinin araştırılması. Yayınlanmamış yüksek lisans tezi, Maltepe Üniversitesi, İstanbul.

Oyserman, D., Bybee, D., Mowbray, C. \& Kahng, S. K. (2004). Parenting self-construals of mothers with a serious mental illness: efficacy burden and personal growth. Journal of Applied Social Psychology, 34(12), 2503-2523.

Önder, A. ve Gülay, H. (2008). İlköğretim sekizinci sınıf öğrencilerinin psikolojik sağlamlığının çeşitli değişkenler açısından incelenmesi. Dokuz Eylül Üniversitesi Buca Eğitim Fakültesi Dergisi, 23, 192-197.

Özcan, B. (2005). Annebabaları boşanmış ve annebabaları birlikte olan lise öğrencilerinin yılmazlık özellikleri ve koruyucu faktörler açısından karşılaştırılması. Yayınlanmamış yüksek lisans tezi, Ankara Üniversitesi, Ankara.

Pakenham, K., Sofronoff, K., \& Samios, C. (2004). Finding in meaning in parenting a child with Asperger syndrome. Research in developmental disabilities, 25, 245-264.

Patterson, J. (2002). Integrating family resilience and family stress theory. Journal of Marriage and Family, 64, 349-360.

Plumb, J.C. (2011). The impact of social support and family resilience on parental stress in families with a child diagnosed with an autism spectrum disorder. Retrieved on September 4, 2011 from http://www.biomedcentral.com/1756-0500/3/310

Raskind, M. H., Goldberg, R. J., Higgins, E. L., \& Herman, K.L. (1999). Patterns of change and predictors of success in individuals with learning disabilities: Results from a twenty- year longitudinal study. Learning Disabilities Research and Practice, 14(1), 35-49.

Richardson, S. A., \& Koller, H. (1992). Vulnerability and resilience of adults who were classified as mildly mentally handicapped in childhood. In B. Tizard \& V. Varma, (Eds.), Vulnerability and resilience in human development (pp. 102-119). UK: Jessica Kingsley Publishers. 
Riggio, H., \& Desrochers, S. J. (2006). Maternal employment: Relations with young adults' work and family expectations and self-efficacy. American Behavioral Scientist, 49(10), 1328-1353.

Rogers, M. A., Wiener, J., Marton, I., \& Tannock, R. (2009). Parental involvement in childrens learning: Comparing parents of children with and without Attention-Deficit/Hyperactivity Disorder (ADHD). Journal of School Psychology, 47(3), 167-185.

Rothaupt, J. W., \& Young, S. (2007). An inquiry of young adults' perceived efficacy and success of intimate relationships: Gender and personality. The Researcher, 21(1), 41-49.

Ryan, L. \& Caltabino, M. L. (2009). Development of a New Resilience Scale: The Resilience in Midlife Scale (RIM Scale). Asian social science, 5 (11), 39-51.

Sanders, M. R., \& Woolley, M. L. (2004). The relationship between maternal self-efficacy and parenting practices: implications for parent training. Child: Care, Health \& Development, 31(1), 65-73.

Scorgie, K., \& Sobsey, D. (2000). Transformational outcomes associated with parenting children who have disabilities. Mental Retardation, 38, 195-206.

Seltzer, M. M., Greenberg, J. S., Floyd, F. J., Pettee, Y., \& Hong, J. (2001). Life course impacts of parenting a child with a disability, American Journal on Mental Retardation, 106, 282-303.

Sezgin, F. (2009). Relationships between teacher organizational committment, psychological hardiness and some demographic variables in Turkish primary schools. Journal of Educational Administration, 47(5), 630-651.

Sipahioğlu, Ö. (2008). Farklı risk gruplarındaki ergenlerin psikolojik sağlamlılıklarının incelenmesi. Yayınlanmamış yüksek lisans tezi, Selçuk Üniversitesi, Konya.

Skehill, C. M. (2001). Resilience, coping with an extended stay outdoor education program, and adolescent mental health. Unpublished Honours thesis, University of Canberra, Australia.

Sofronoff, K., \& Farbotko, M. (2002). The effectiveness of parent management training to increase self-efficacy in parents of children with Asperger Syndrome. Autism, 6(3), 271-286.

Sojo, V., \& Guarino, L. (2011). Mediated moderation or moderated mediation: relationship between length of unemployment, resilience, coping and health. The Spanish Journal of Psychology, 14(1), 272-281.

Sun, J., \& Stewart, D. (2007). Age and gender effects on resilience in children and adolescents. The International Journal of Mental Health Promotion, 9(4), 16-25.

Svavarsdóttir, E. K., \& Rayens, M.K. (2003). American and Icelandic parents' perceptions of the health status of their young children with chronic asthma. Journal of Nursing Scholarship, 35(4), 351-358.

Svavarsdóttir, E.K., \& Rayens, M.K. (2005). Hardiness in families of young children with asthma. Journal of Advanced Nursing, 50(4), 381-390.

Towsend, A., Noelker, L. Deimling, G., \& Bass, D. (1989). Longitudinal impact of interhousehold care giving on adult children's mental health. Psychology and Aging, 4, 393-401.

Trute, B. (1990). Child and parent predictors of family adjustment in households containing young developmentally disabled. Family Relations, 39, 292-297.

Tsibidaki, A., \& Tsamparli, A. (2009). Adaptability and cohesion of Greek families: raising a child with a severe disability on the island of Rhodes. Journal of Family Studies, 15, 245-259.

Van Riper, M., Ryff, C., \& Priadham, K. (1992). Parental and family well-being in families of children with Down syndrome. Research in Nursing and Health, 15, 227-235. 
Walsh, F. (2006). Strengthening Family Resilience (2 nd ed.). New York: Guilford Publications.

Werner, E. E. (1993). Risk, resilience, and recovery: Perspectives from the Kauai longitudinal study. Development and Psychopathology, 5, 503-515.

Wowra, S. A., \& McCarter, R. (1999). Validation of the Empowerment Scale with, an outpatient mental health population. Psychiatric Services, 50(7), 959-, 961.

Yalım, D. (2007). First year collage adjustment: The role of coping, ego-resiliency, optimism, and gender. Yayınlanmamış yüksek lisans tezi, Ortadoğu Teknik Üniversitesi Sosyal Bilimler Enstitüsü, Ankara. 


\section{Summary}

\section{Investigating Perception of Parental Resilience in Terms of Some Variables}

\author{
Sema Kaner* \\ Ankara University
}

\author{
Hatice Bayraklı* $^{* *}$ \\ Kemal Yurtbilir Early Childhood \\ Education Center
}

\author{
Cem Oktay Güzeller ${ }^{* * *}$ \\ Akdeniz University
}

\section{Introduction}

Resiliency refers to an active process providing rebound from adversity more strengthened, leading to endurance and growth in response to crisis (Walsh, 2006). Resilience is seen not only in individual but also in family and social level (Greene \& Livingston, 2002). In family level, while some families become stronger and do well in the face of stress or crisis, others do not. According to Patterson (2002) resilience in the family is an active process and an ability to cope with difficulties and achieve a new balance.

Recently, there is a growing interest in family resilience. However, there is a limited number of studies about families with disabled children (i.e., Bower, Chant, \& Chantwin, 1998; Campbell-Sills, Forde, \& Stein, 2009; Ha, Hong, Seltzer, \& Greenberg, 2008; Li-Tsang, Yau, \& Yuen, 2001; Olsson ve Hwang, 2008; Olsson, Larsman, \& Hwang, 2008; Plumb, 2011; Svavarsdottir ve Rayens, 2003; Tsibidaki ve Tsamparli, 2009; Van Riper, Ryff, \& Priadham, 1992).

In Turkey, resilience studies mostly focused on adolescents (e.g. Dayığlu, 2008; Eminağaoğlu, 2006; Gizir, 2004; Gürgan, 2006; Kaya, 2007; Özcan, 2005; Sipahioğlu, 2008; Yalım, 2007). There is only one study conducted with adults (Kararrmak, 2007). Boyraz \& Sayger (2011) investigated psychological well-being with

\footnotetext{
* Prof. Dr. Ankara University, Faculty of Educational Sciences, Department of Special Education, Emeritus Professor, Ankara, E-mail: semakaner@gmail.com

** Specialist. Kemal Yurtbilir Early Childhood Education Center Preschool and Primary School for Children with Hearing Impairment, Ankara, E-mail: hbayrakli@yahoo.com

*** Assist. Prof. Dr. Akdeniz University, Faculty of Education, Department of Educational Sciences, Antalya, E-mail: cguzeller@gmail.com
} 
parents of disabled children. Family resilience studies in special education begins with Kaner \& Bayraklı's researches (Bayrakl1, 2010; Bayraklı \& Kaner, 2010, 2012; Kaner \& Bayrakl1, 2009, 2010, in press, 2010). In these studies Kaner and Bayraklı focused on relationships between maternal resilience, perceived quality and quantity of the social support system and coping styles.

There are also few studies investigated both parents' (Campbell-Sills at al., 2009; Ha et al., 2008; Patterson, 2002) and children's characteristics such as age, gender, education level, family income (Ha et al., 2008). In Turkey, there is no research with these independent variables in resilience. So, the present study will investigate parents' resilience perceptions regarding parental age, gender, education level and having a child with disability or not.

\section{Method}

The subjects of the study consist of parents of 524 children. Of the 524 participants, $105(\% 20.0)$ were parents of children with intellectual disability, while $419(\% 80.0)$ were parents of typically developing children. The range, mean, and standart deviation of the parents' age were 20-63, 38.86 ve 7.45, respectively.

Parental Resiliency Scale-PRS developed by the authors was used in this study. PRS consist of 37 items and four subscales (Challenge, Self-Efficacy, Commitment to Life, and Control). Each item is measured on a 5point Likert scale (I can definetely do $=5$, I can generally do $=4$, I can do $=3$, I can sometimes do $=2$, I can not definetely do $=1)$.

Correlations between the scores of PRS and Parental Self-Efficacy Scale and Rosenbaum's Learned Resourcefulness Scale were $(0.18-0.50, \mathrm{p}<0.001)$ and $(0.45-0.58, \mathrm{p}<0.001)$ respectively. Divergent validity coefficients between PRS and Beck Depression Inventory were significantly negative ( -0.18 and -0.36 , $\mathrm{p}<0.0001)$. The Cronbach alphas, Spearman-Brown split half and test-retest coefficients were 0.54-0.91, 0.530.87 and $0.33-0.80$ respectively.

\section{Analysis}

Data was analyzed with SPSS programme. Frequencies, percentiles, means, standart deviations were computed. MANCOVA test was conducted in order to determine whether resiliency beliefs of the parents' differ significantly in terms of the four independent variables: child (disabled/typically developing), parental age, gender and educational level.

\section{Results}

Results showed that parents of typically developing children perceived themselves more resilient in Challenge $[\mathrm{F}(1,511)=3.788, \mathrm{p}<0.052]$, Self-Efficacy $[\mathrm{F}(1,511)=7.712, \mathrm{p}<0.006]$, Commitment to Life Subscales $[\mathrm{F}(1,511)=8.344, \mathrm{p}<0.004]$, and Total $[\mathrm{F}(1,511)=6.516, \mathrm{p}<0.011]$ than the other parent group; mothers were more resilient than fathers in the subscale of Self-Efficacy $[F(1,511)=8.793, p<0.003]$; parental resilience decreased by growing age in Self-Efficacy $[\mathrm{F}(2,511)=4.465, \mathrm{p}<0.012]$ and Commitment to Life $[\mathrm{F}(2,511)=3.687, \mathrm{p}<0.026]$ subscales. Lastly, there were no significant interaction effects in parents' resilience perceptions between groups based on independent variables.

\section{Discussion}

It is difficult to discuss results of the present study because there are few research regarding parental resilience in terms of parents' age, gender, education level and having a child with disability or not. Literature showed contradictory results based on these independent variables. Certainly, the methodological differences (sampling, instruments, statistical techniques, etc.) are effective factors in these conflict findings. Besides, the number of subjects in two parental groups in present study is not equal. Also, parents of children with and without disability were analyzed together according to some variables (i.e., gender, age, education level). These independent variables should be investigated separately with these two parent groups. Some suggestions may be 
offered to conduct further studies concerning parental resilience. Some of our findings will be better understood after the studies will that examine the parental resilience in relation to the factors such as family income, parents' job status, existence of another child with disability in the family, age of child and parents when the child is diagnosed, parents' well-being, social support services available for the family, parents' coping styles, children' characteristics (age, gender, types of different disability, etc.). The present study is cross-sectional-the variables have only been measured at one time. The changes in parental resilience should be investigated by conducting longitidunal studies so drawbacks of our cross-sectional study may be overcome. 
